\title{
A QUANTITATIVE MEASUREMENT \\ OF WATER-VAPOR IN THE ATMOSPHERE OF VENUS (*)
}

By Murk Botrman, William Plummer and John Strong

(The Johns Hopkins University, Baltimore, Maryland, U. S. A.)

Résumt. - L'existence de la vapeur d'eau dans l'atmosphère de Vénus a été découverte en Novembre 1959 au moyen d'observations faites par l'équipage d'un ballon à 80000 pieds $(24500 \mathrm{~m})$. Ce résultat a été confirmé par des mesures beaucoup plus précises en Février 1964 obtenues au moyen d'un appareil non piloté. On décrit les méthodes employées pour observer la bande d'absorption à 1,13 $\mu$ de la vapeur d'eau de Vénus et l'interprétation de ces données.

ABsTraOT. - Water vapor in the atmosphere of Venus was discovered in November 1959 by observations made at 80000-ft. altitude with a manned balloon-telescope system. This result was confirmed and measured far more precisely in February 1964 with an automatic unmanned system. The method of observing Venus water-vapor absorption in the 1.13- $\mu$ band, and the interpretation of that absorption, are described.

Резюме. - Существование водяного пара в атмосфере Венеры было открыто в ноябре 1959 г. при посредстве наблюдений совершенных экипажем воздушного шара на 80.000 футов высоты (24.500 м.). Этот результат был подтвержден более точными измерениями в феврале 1964 г, полученными при посредстве неуправляемого аппарата. Описаны методы, употребленные для наблюдөния полосы поглощения в 1,13 водяного пара Венеры, и интерпретация этих данных.

\section{INTRODUOTION}

In February of this year a determination of water vapor in the upper atmosphere of Venus was made. The amount of water found above the planet's clouds is of the same order of magnitudes as in the earth's stratosphere. This measurement settles the question of the presence of water on Venus.

The quantity measured is in agreement with the upper limit of the 1959 measurements, from a manned balloon flight of Moore and Ross. The accuracy, however, is much greater. The relative error is only $5 \%$.

The data were obtained by an automatic telescope-spectrometer unit, carried by balloon to an altitude of $27 \mathrm{~km}$. There was no observer on board. The telescope, of $30 \mathrm{~cm}$ aperture, was pointed at Venus by the tracking system that was described by Strona and Bottema in last year's Colloquium Reports [1]. An over-all picture of the unit, asit ascended from Holloman Air Force Base, New Mexico, on February 21, 1964, is given in Figure 1 and Figure 2 show the equipment inside the dome.

$\left(^{*}\right)$ This research was supported by the Office of Aerospace Research, U. S. Air Force, Contract AF 19 (628)-202.
This paper discusses some aspects of the data recording system, the data reduction and the in ter pretation of the results in the light of our present knowledge of the atmosphere of Venus.

\section{Data Recording}

The radiation was measured in the band at 1.13 microns, with a grating spectrometer of $2 \AA$ resolving power. The spectrum was imaged upon a thin stainless steel strip perforated by 21 exit slits, each of $1.4 \AA$ spectral width, placed at positions corresponding with minima in the water-

TABLE I

Positions of EXIT SLITS

\begin{tabular}{|c|c|c|c|c|c|}
\hline$a$ & $11149 \AA$ & $h$ & $11218 \AA$ & 0 & $11276 \AA$ \\
\hline$b$ & 11164 & $i$ & 11222 & $p$ & 11295 \\
\hline$c$ & 11171 & $j$ & 11225 & $q$ & 11322 \\
\hline$d$ & 11181 & $k$ & 11235 & $r$ & 11332 \\
\hline$e$ & 11187 & $l$ & 11252 & $s$ & 11337 \\
\hline$f$ & 11201 & $m$ & 11260 & $t$ & 11345 \\
\hline$g$ & 11211 & $n$ & 11271 & $u$ & 11358 \\
\hline
\end{tabular}



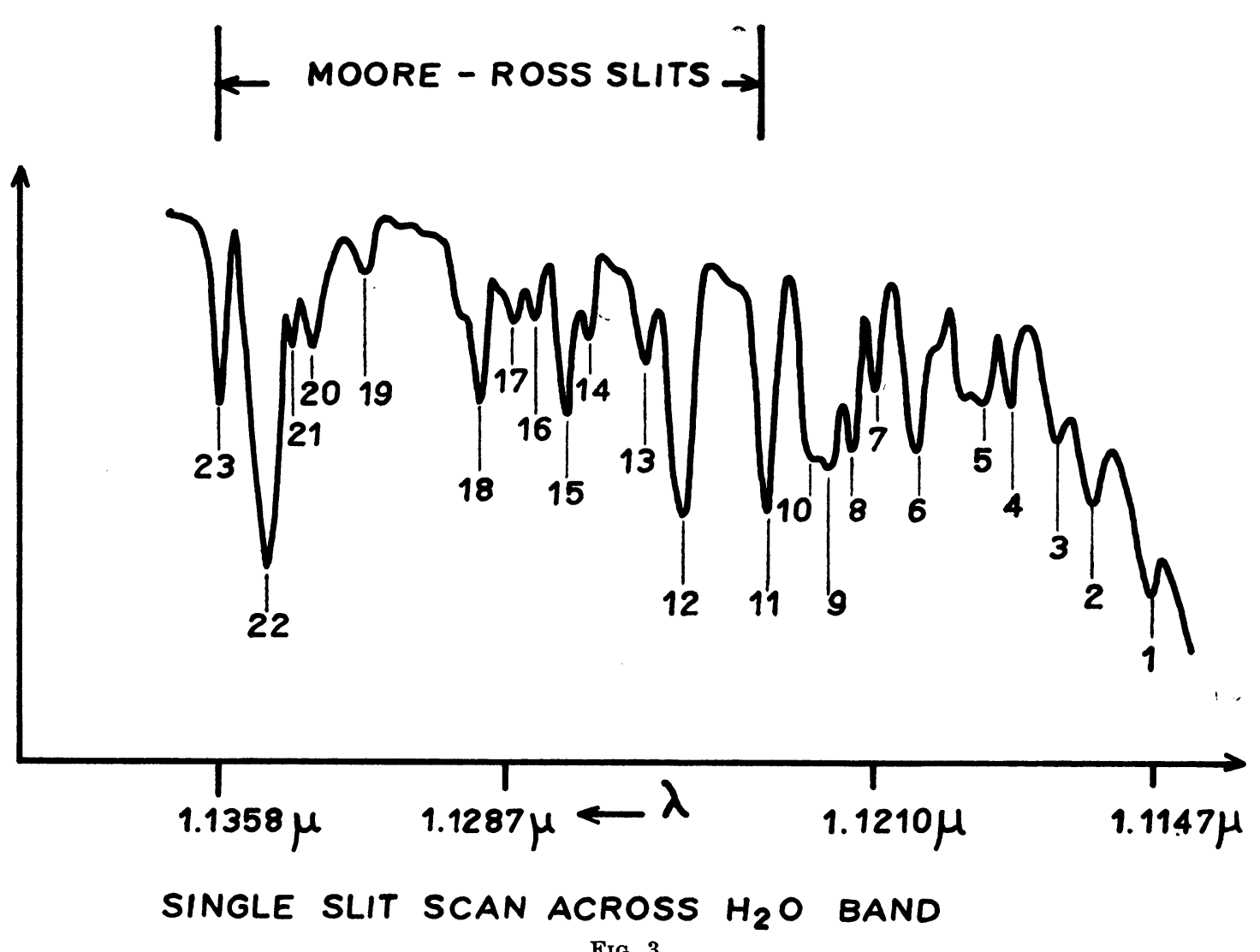

Fia. 3.

vapor spectrum, as shown in Figure 3. The positions of the slits are indicated by numbers 1 through 15, and 18 through 23 . In the table, the positions are in the same order, and designated by letters.

While sampling the data, the array of slits was driven back and forth about the spectrum-matching position over a range equivalent to a spectral width of $16.7 \AA$. Each scan had a time duration of 10 seconds. Water-vapor absorption, in the optical path, was manifest as a minimum at the spectrum-matching position, the depth of the minimum being a measure for the amount of water-vapor penetrated by the radiation. An advantage of scanning the slits is that slight changes in wavelength calibration, brought about by the environment at altitude, are eliminated. In the off-match position some slits may still be aligned with regions of absorption, which leads to a reduction of the modulation. This effect, however, is very small for the displacements used, and is easily accounted for by calibration.

The radiation entering the spectrometer was chopped at a frequency of $30 \mathrm{cps}$. The detector used was a photomultiplier with an S-1 photo- cathode, selected for sensitivity in the near infrared. The AC component of its response was ampli fied and recorded on photographic paper by mirror galvanometers. A typical section of the flight record is shown in Figure 4.

Three galvanometers, with the same zero line but differing sensitivities, were used to assure a wide dynamic range. The strip on which galvanometer deflections were recorded also carried records of the error signals of the Venus tracker. These records were useful to identify spurious changes in signal level, caused by small irregularities in tracking. From 120 scans, selected for high-tracking stability, the modulation due to water vapor in the path was derived to be $(10.5 \pm 0.5) \%$. No systematic variation in the modulation depth appeared during the two hours of observation. The observation period extended from 2 to $4 \mathrm{o}^{\prime}$ clock in the afternoon, and Venus culminated around 3 o'clock.

In addition to the water-vapor minimum, another dip in galvanometer response occurs at the point in the scan where slit " $p$ " (in Table I) came into position to pass the mercury emission line at $11287 \AA$. This was produced by radiation 


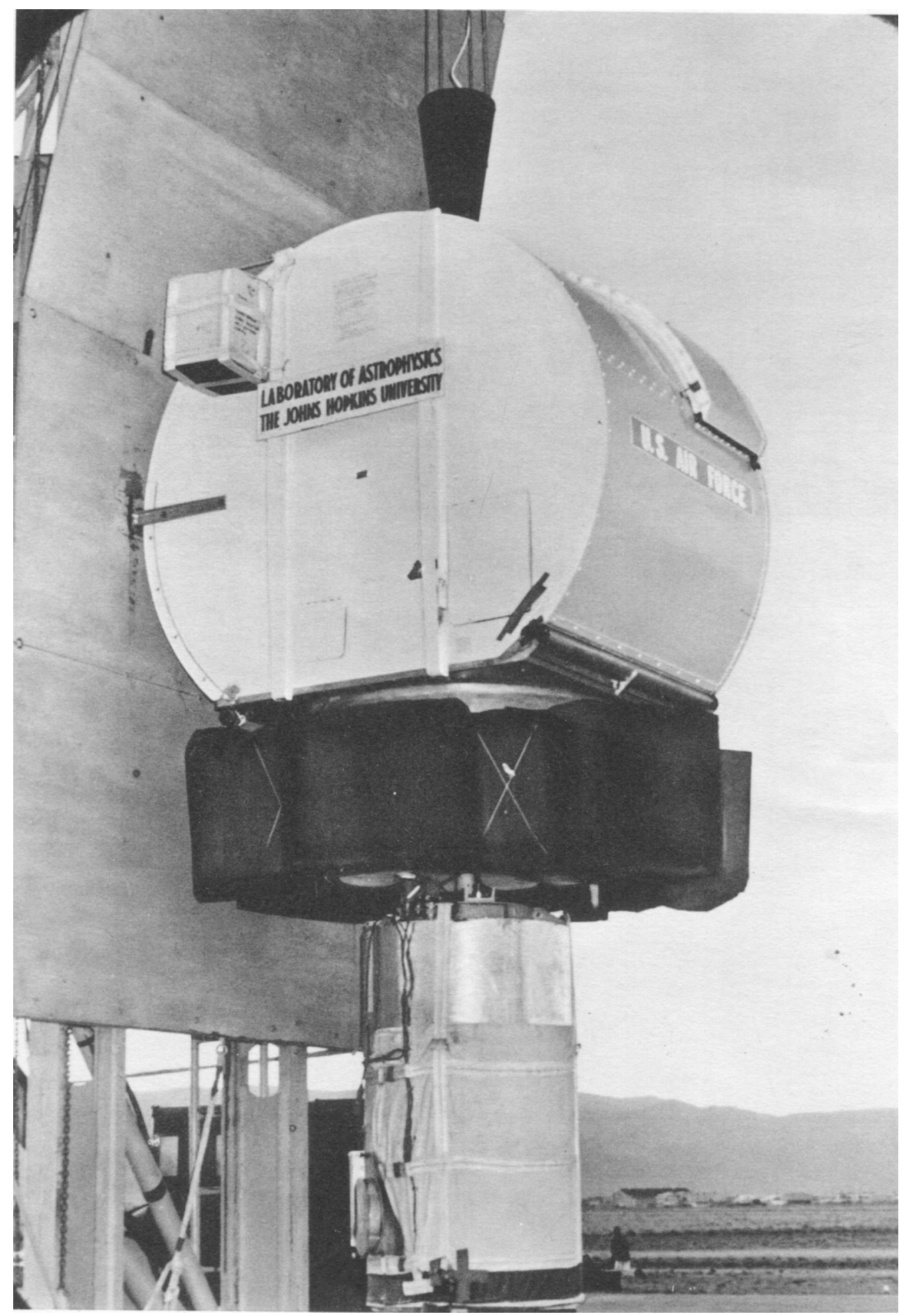

Fig. 1 


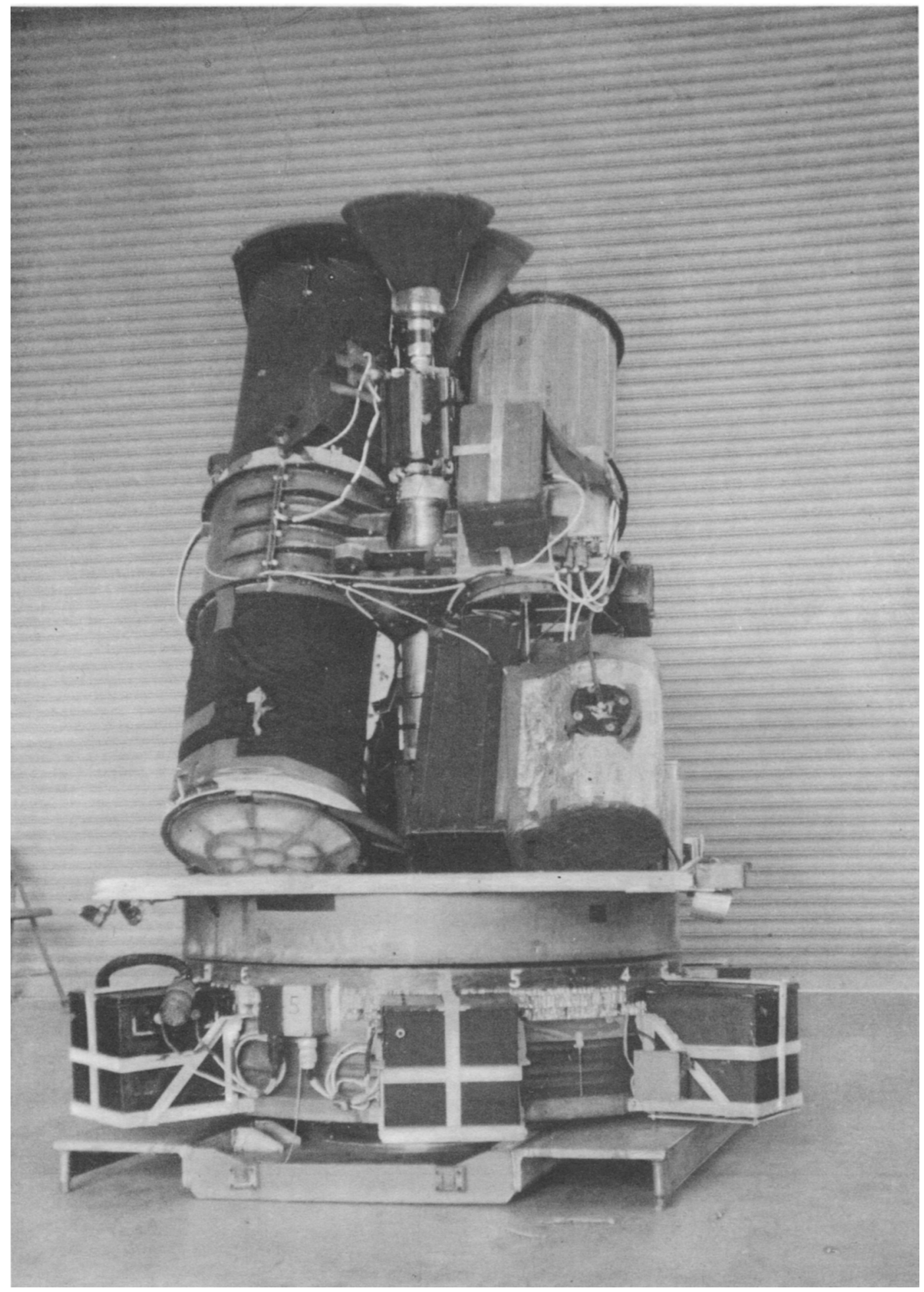

Fig. 2

BOTTEMA, PLUMMER, STRONG (VI-3) 


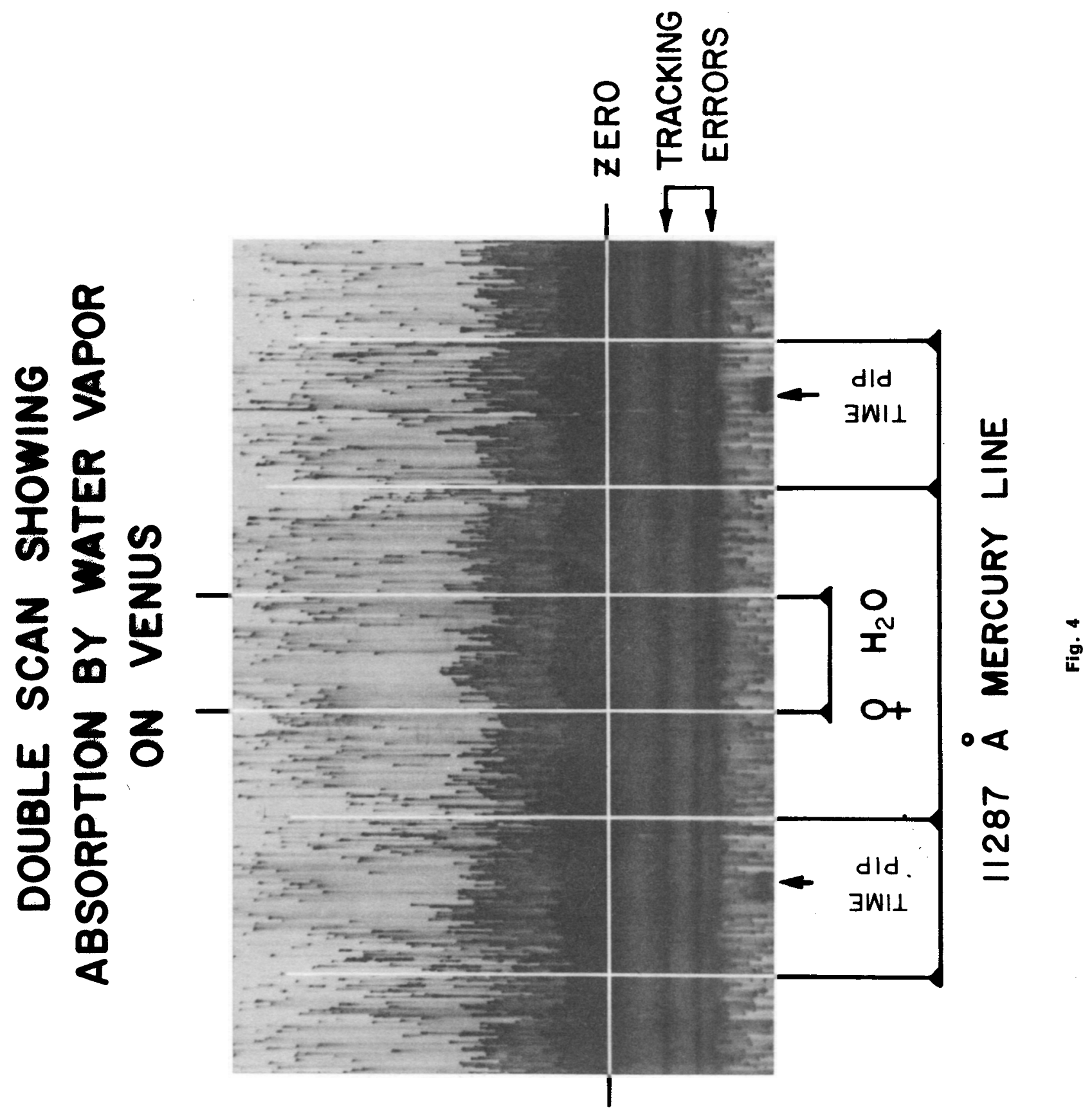




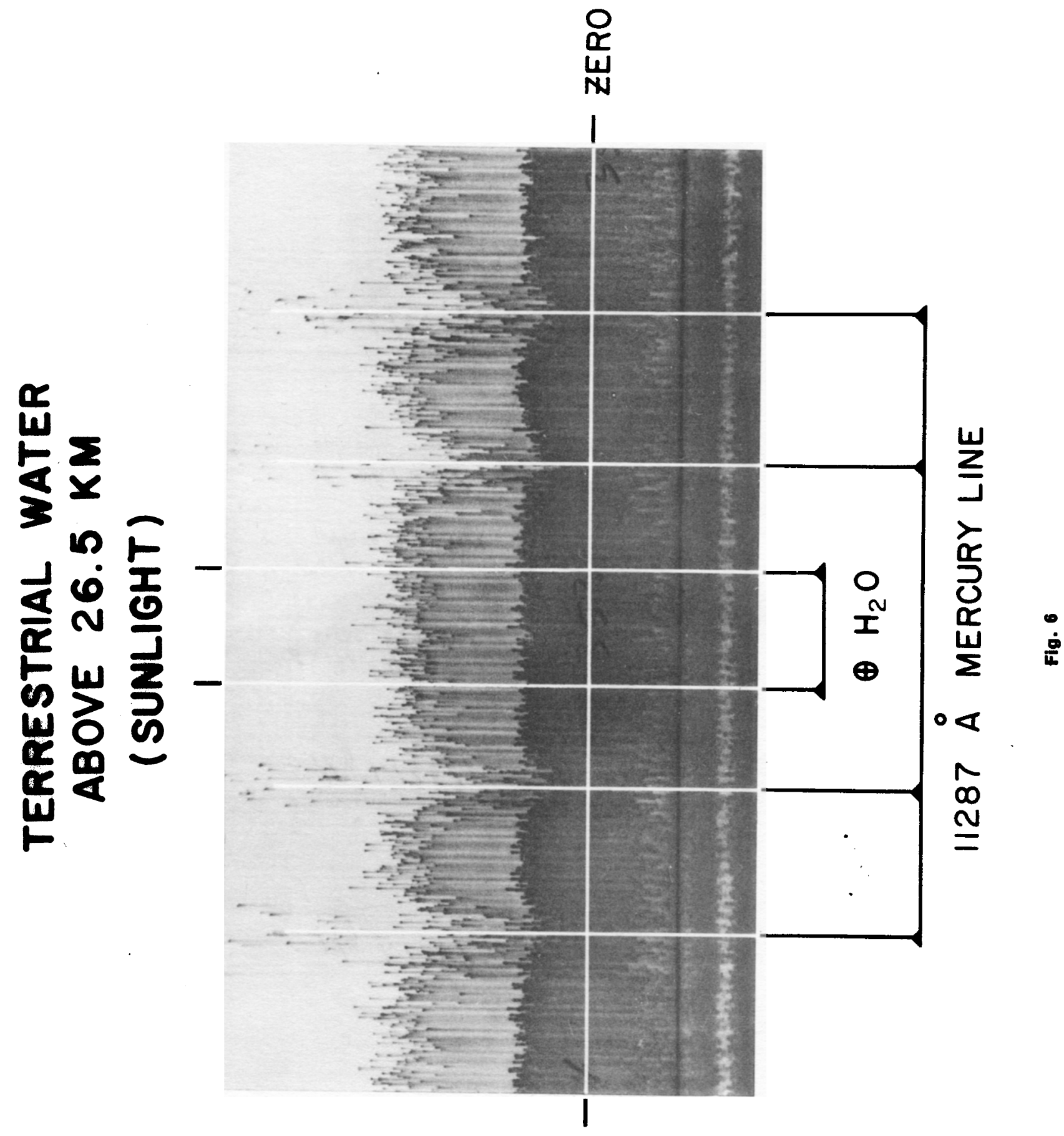


from a low-pressure mercury arc lamp. The lamp was positioned near the entrance slit, so that its emission was scattered into the spectrometer from the back of the chopper blade. The mercury line, when it fell on slit " $p$ ", appeared as a dip in the recorded signal since its radiation was received in the negative half-cycle of the chopper.

The recorded data thus had two dips during each scan : one resulting from absorption by water vapo, and one resulting from the off-cycle mercury emission. The position of the watervapor dip with respect to the mercury dip gives us a measure of the DoPPLER shift in the radiation received from Venus. Twenty of the cleanest scans were selected and carefully measured. The Doppler shift thus found was $(0.49 \pm 0.05) \AA$, in excellent agreement with the value calculated from the relative orbital motions of Venus and the earth, which at the time of observation was $0.495 \AA$.

\section{Data Reduction}

The instrument was calibrated at sea level pressure before flight, in a room with measured humidity. The calibration curve is shown in Figure 5.
This calibration is in agreement with calculations of Dr. William S. BENEDICT, of this laboratory, for the resolving power of our instrument. Dr. BENEDICT's calculations, made for our less successful 1959 flight, were for the latter twothirds of the 21 slits in our array, but the seven slits which have been added correspond to absorption lines of similar strengths. The $10.5 \%$ modulation, found in flight, corresponds to $9.8 \times 10^{-3} \mathrm{~g} / \mathrm{cm}^{2}$ of precipitable water at one atmosphere, at room temperature.

The amount of water vapor detected must still be corrected for residual water vapor in the earth's atmosphere above the level of the balloon. At the end of the Venus measurement, doors closed over the telescope. The doors were provided with an opening covered with thin white cloth, to receive sunlight and scatter it into the telescope. The modulation thus measured was less than $1.0 \%$. A typical scan is shown in Figure 6. The solar elevation at this time was about $20^{\circ}$. The elevation of Venus, at culmination, was $62^{\circ}$. It seems therefore that at the time of the Venus observation the terrestrial contribution in the modulation was about $0.5 \%$.

Both assessments of terrestrial water vapor,

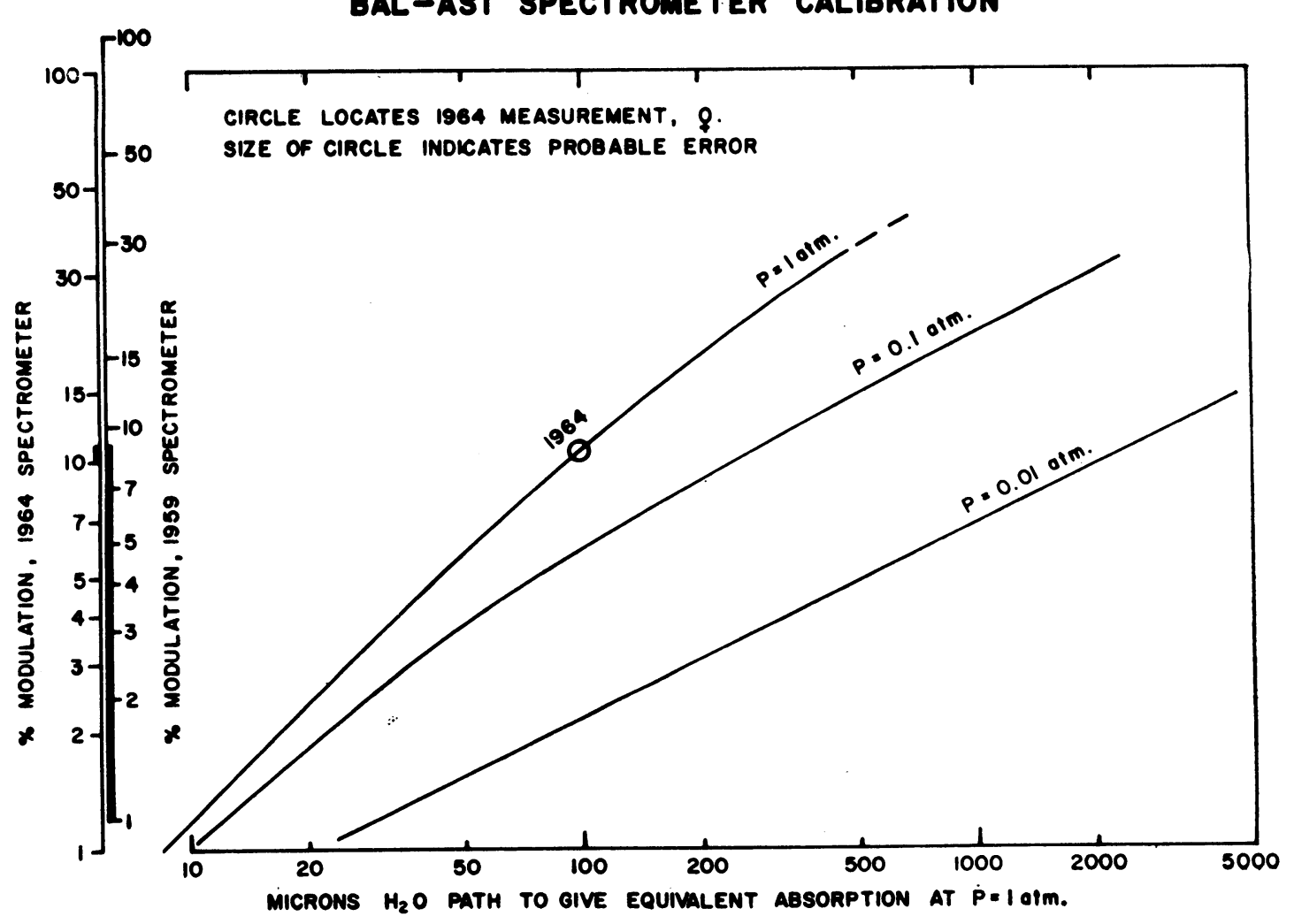

Fia. 5. 
by DopPLER shift and by sunlight measurement, are in fair agreement with the currently accepted value of about $7 \times 10^{-4} \mathrm{~g} / \mathrm{cm}^{2}$ of water above the altitude of the balloon. The extension of our laboratory water-vapor calibration to the lower pressures at altitude is based again upon the calculations made by Dr. Benedict.

Since the Doppler shift between Venusian and terrestrial water absorptions is sufficiently greater than the equivalent width of either, we may directly subtract out the modulation measured with sunlight from the modulation measured with Venus, even though we are not operating in the linear absorption region. The Venus water dip is thus corrected from $10.5 \%$ to $10.0 \%$.

\section{INTERPRETATION}

To interpret the absorption in terms of watervapor quantities on Venus, it is necessary to assume a range of pressures from the cloud deck outward. In the following, we have supposed that the water vapor above the visible clouds is distributed gravitationally, with a uniform mixing ratio. For the base pressure we have used the limits reported in the survey article by SAGAN [2] : $90 \mathrm{mb}$ to $600 \mathrm{mb}$ at the cloud level. To treat the gravitational pressure distribution we assume a LORENTz line shape, and perform two integrations. One integration is over the altitude above the Venusian cloud deck, from zero to infinity. The other integration is over wavelength, from the center of the absorption out to the edges of the slit, which may be taken as \pm infinity. These integrations yield a correction factor, which must lie between 1 and $\sqrt{2}$, by which the measured $10.0 \%$ modulation must be multiplied before reading the calculated calibration curve for a uniform atmosphere at the base pressure. For the $600 \mathrm{mb}$ base pressure the absorption measured is nearly in the linear region, and the result may be taken as $1.1 \times 10^{-2} \mathrm{~g} / \mathrm{cm}^{2}$. The $90 \mathrm{mb}$ case is nearly in the square-root region, and the result is $4.7 \times 10^{-2} \mathrm{~g} / \mathrm{cm}^{2}$.

At the time of our observation the phase angle of Venus was $65^{\circ}$. The average slant path through the Venusian atmosphere, assuming cosine scattering from the cloud deck and integrating over the visible surface, was 3.82 times the vertical path through the atmosphere.

When the values found are divided by 3.82 for the slant path correction, the results are $12.3 \times 10^{-3} \mathrm{~g} / \mathrm{cm}^{2}$ for the $90 \mathrm{mb}$ case, and $2.9 \times 10^{-3} \mathrm{~g} / \mathrm{cm}^{2}$ for the $600 \mathrm{mb}$ case.

A choice between these values, or in this range, must await more knowledge about the actual pressures. It is interesting, however, to note that values reported for comparable levels in the earth's upper atmosphere [3] represent the geometric mean of the extremes we have calculated for the planet Venus.

Manuscrit reçu le 9 octobre 1964.

\section{REFERENCES}

[1] Strona J. and Bottema M., 1964, Mémoires Soc. $R$. Sc. Liège, cinquième série, IX, 528.

[2] SaGAN C. and KmLlog W. W., 1963, Ann. Rev. Astro. and Astrophys., 1, 235.
[3] Gutnor M., 1962, Air Force Surveys in Geophysics, $n^{\circ} 147$. 